\title{
Desplazamiento forzado trans*fronterizo: mujeres trans* de Centroamérica en México
}

\author{
Alix Lorena Almendra ${ }^{1}$
}

ISSN: 2350-0844

п. I2, v. I nov.2019-abr.2020

p. Bl-IOQ.

RESUMO: Este artigo aborda a complexidade dos processos de identidade que ocorrem na experiência do deslocamento forçado de mulheres trans* da América Central no México. As perguntas, quais são as condições de deslocamento das pessoas trans* da América Central? E como a experiência de um trânsito migratório mudou para a demanda por reconhecimento do status de refugiado? Estas questões são o ponto de partida para analisar os contextos das experiências de trânsito migratório, sexual e de gênero. A análise é realizada com base em uma abordagem etnográfica no abrigo para migrantes "La 72", com o objetivo de explorar as trajetórias de vida das mulheres trans* migrantes, bem como a maneira pela qual ocorrem deslocamentos múltiplos - territorial, institucional, identidade, etc. - e modificações, não apenas no processo migratório, mas também nos sujeitos que o vivenciam.

PALAVRAS-CHAVE: Trânsitos, Deslocamento Forçado, Refúgio, Transgêneros, América Central.

Abstract: This article tackles the complexity of the identity processes involved in the experience of displacement of Central American trans* women in Mexico. The questions underlying the nature of the conditions of the displacement of Central American trans* individuals and the way the experience of migratory transit has shifted to demands for refugee status recognition serve as the starting point to analyze the contexts of the experiences of migatory, sexual, and gender transit. The analysis is based on an ethnographic study of the trans people shelter "La 72 ", aiming to explore the trajectories of migrant trans* women, as well as the way the multiple displacements -territorial, institutional, identitarian, etc.-- and modifications occur, not only on the migratory process, but also on the subjects going through it.

Keywords: Transits, Forced Displacement, Refuge, Transgender women, Central America.

Resumen: En el presente artículo se aborda la complejidad de los procesos identitarios que ocurren en la experiencia de desplazamiento forzado de mujeres trans* centroamericanas en México. Las preguntas ¿cuáles son las condiciones del desplazamiento de las personas trans* centroamericanas? y ¿cómo se ha desplazado la experiencia de un tránsito migratorio a la demanda de un reconocimiento de la condición de refugiadas? son el punto de partida para analizar los contextos de las experiencias del tránsito migratorio, sexual y de género. El análisis se realiza a partir de una aproximación etnográfica en el albergue para personas migrantes "La 72", con el objetivo de explorar las trayectorias de vida de mujeres trans* migrantes, así como la forma en que se producen múltiples desplazamientos -territoriales, institucionales, identitarios, etc.- y modificaciones, no sólo en el proceso migratorio, sino en los sujetos mismos que lo experimentan.

Palabras clave: Tránsitos, Desplazamiento, Refugio, Mujeres trans*, Centroamérica.

${ }^{1}$ Doctoranda en el Programa del Doctorado en Humanidades de la Universidad Autónoma Metropolitana-Xochimilco, Máster en Estudios de Género por el Colegio de México. E-mail: aalmendra@colmex.mx 


\section{Introducción}

El presente artículo se desprende de una investigación académica que tuvo el objetivo de explorar la experiencia migratoria de personas trans* centroamericanas en tránsito dentro del territorio mexicano. En esta exploración, tanto el campo de la sexualidad como el campo de los estudios migratorios fueron ejes centrales para abordar las trayectorias de vida de estas mujeres.

El término trans* con asterisco se ha decidido utilizar con la intención de escribir desde un lugar no esencializante, sobre la sexualidad y las posiciones de género. Este término hace referencia a una reflexión sobre las posibilidades de una ruptura con el lenguaje binario, que plantea trans* como concepto "paraguas" para incluir diversas expresiones e identidades de género, como son transgénero, transexual, travesti, etc. (Cabral, 2009). Desde esta propuesta, lo que se añade es una multiplicidad para concebir el cuerpo, la identidad y las experiencias sociales y políticas que van más allá de las normas sociales binarias impuestas. A lo largo del presente artículo se hace referencia a las personas trans* también como mujeres trans*, ya que el grupo de personas interpeladas durante la investigación también hizo uso de este término para posicionarse y nombrarse.

En relación con la experiencia de tránsito de las personas trans*, es importante considerar la multiplicidad de tránsitos que ocurren en las trayectorias de estas personas. Partimos del reconocimiento de que este tránsito es un movimiento de huida, un desplazamiento que no puede explicarse en su totalidad con los discursos existentes para explicar los desplazamientos de la región, pero que tampoco suceden fuera de estos contextos.

Como punto de partida en la discusión conceptual sobre los movimientos migratorios tomamos la diferencia que propone Gómez-Johnson (2015) entre la migración forzada y el proceso migratorio "clásico". El carácter forzado de un desplazamiento aparece cuando la decisión de partir es más bien un imperativo, una manera de preservar la vida. Este movimiento no es lineal, sino que consta de varios desplazamientos internos previos que pueden convertirse eventualmente en internacionales. Además, la salida no se da en busca de mejoras económicas o para encontrarse con familiares en el exterior, por lo que no tiene como resultado el envío de remesas, sino que es provocada por la vulneración de derechos básicos que no pueden ser garantizados por el Estado o que son violados por él. 
En el contexto migratorio también se hace uso del concepto de desplazamiento interno forzado, que se define como los "movimientos de población obligada a huir o dejar sus hogares o sus lugares de residencia habituales como resultado de los efectos causados por conflictos armados, situaciones generalizadas de violencia, violaciones a derechos humanos, o bien desastres naturales o causados por el hombre, población que no ha cruzado una frontera internacional reconocida entre dos Estados" (Kälin, 2005).

González Gil (2015), sin embargo, identifica que el concepto de desplazamiento interno forzado, generalmente, encuentra limitaciones debido al proceso de internacionalización que termina mostrando la otra dimensión del problema: la movilidad transfronteriza bajo condiciones forzadas. Esta nueva dimensión produce otros tipos de desplazamientos conceptuales. Primero, surge la cuestión del desplazamiento forzado como una categoría de análisis que pone en cuestión los criterios con los cuales suele ser interpretado el fenómeno migratorio centroamericano, en tanto resultado de una decisión voluntaria, aspiracional y con fines económicos. En segundo lugar, al llevarse a cabo mediante un atravesamiento transnacional, aparece la sustitución de la figura del desplazado por la del refugiado, es decir, la persona que necesita protección internacional.

En el contexto de la migración centroamericana es necesario ubicar el análisis de esta movilización como un desplazamiento forzado transfronterizo, que obliga a miles de personas a dejar sus hogares con la intención de poner a salvo su vida. Sin embargo, en el caso de las personas trans*, estas razones, además de intensificarse, adquieren otro matiz.

En los tránsitos de las mujeres trans* centroamericanas es importante ubicar una salida forzada, no sólo de los países de origen, sino de los lugares donde se conoció la vida en sus primeros años: el hogar, la familia, el barrio, la comunidad, la escuela. Estos desplazamientos fueron extendiéndose (en tiempo y espacio) más allá de las fronteras y articulándose con los procesos migratorios históricos transnacionales de la región Estados Unidos-MéxicoCentroamérica. En este escenario se producen vidas en desplazamiento como condición de existencia. Se trata de vidas que sólo pueden transcurrir en múltiples tránsitos y movimientos forzados permanentes. Son movimientos empujados por la búsqueda de un nuevo cuerpo y de una identidad deseada; pero también por el imperativo de salvar la vida, así como por alcanzar un reconocimiento simbólico y social que permita el disfrute de ciertos derechos mínimos para vivir dignamente. 
Las experiencias analizadas en este desplazamiento forzado trans*fronterizo son las de personas trans* provenientes de Honduras, El Salvador y Guatemala. Estas mujeres trans* fueron interpeladas en distintos albergues de la Ciudad de México y, en ese momento, el único albergue para migrantes en el país que contaba con un dormitorio para personas identificadas como parte de la comunidad LGBTI, localizado en la ciudad fronteriza de Tenosique, Tabasco. Se trata del Hogar-Refugio para Personas Migrantes La 72, en donde se realizó un trabajo de campo durante casi tres meses en el verano del 2017. En este trabajo de campo se formó parte del equipo de trabajo voluntario del albergue, compartiendo el espacio cotidiano con todas las personas migrantes que ahí se encontraban alojadas. Esta situación permitió un acercamiento etnográfico realizado a través de abundantes notas de diario de campo, herramientas de observación participante, así como entrevistas a profundidad a las personas trans* con quienes se compartía la vida diaria en el albergue.

Las preguntas centrales que guiaron los objetivos de esa investigación fueron: ¿cómo se relaciona la impugnación de los mandatos de género que realizan los cuerpos trans* con las violencias atravesadas en su proyecto migratorio? y ¿cómo se experimenta ese tránsito en relación con la experiencia singular del género y la sexualidad?

Frente al desplazamiento en Centroamericana de mujeres trans*, se sostuvo la hipótesis de que estas personas, en su tránsito, padecían una multiplicación de muros que se extienden en una frontera vertical que produce otro tipo de fronteras relacionadas con las posiciones interseccionales de estas mujeres, donde aparecen lógicas singulares de exclusión. Esos muros o fronteras internas (Fernández Bessa, 2008) van configurando ciertos límites y posibilidades dentro de un contexto de violencia particular, en tanto que se encuentran relacionados con su expresión de género y el ejercicio de una sexualidad que subvierte los mandatos de la sexualidad normalizada y se configura transgrediendo también las fronteras geográficas y políticas del Estado-Nación.

Para exponer la experiencia situada del tránsito de estas personas trans* centroamericanas en Tenosique, Tabasco, nos enfocaremos en dos preguntas particulares: ¿cuáles son las condiciones del desplazamiento de las personas trans* centroamericanas? y, ¿cómo se ha desplazado, en las personas trans*, la experiencia de un tránsito migratorio a la demanda de un reconocimiento de la condición de refugiadas? Esta última pregunta aparece en el contexto del 
trabajo de campo, donde la totalidad de las personas trans* que se encontraban alojadas en el albergue La 72, durante la investigación, habían decidido solicitar asilo en México.

Para esta exposición se presentan tres apartados: el primero, "Ser trans* migrante en México y Centroamérica", donde se pretende aportar algunos datos relevantes al contexto. El segundo apartado es sobre las "Condiciones del desplazamiento forzado trans*fronterizo", donde, a través de relatos de las mujeres trans*, se reconstruye un proceso de desplazamientos continuos en el que se ha dado el trayecto antes de la llegada a México. Posteriormente, se presenta el apartado "De migrantes irregulares al reconocimiento de la condición de refugio", donde se exploran algunos procesos que emergen en el tiempo de la espera. Finalmente, se exponen las conclusiones con algunas consideraciones finales como futuras propuestas de investigación.

\section{Ser trans* migrante en México y Centroamérica: algunos datos de la región.}

En el último informe realizado en el 2016 por La 72, encontramos que en ese año recibieron a 43 personas que se identificaron como parte de la comunidad LGBTI, lo que equivale a un $2 \%$ de la población total que transitó por el albergue durante ese mismo periodo de tiempo. Sin embargo, de estas 43 personas, un 30\% empezó un proceso de regularización migratoria, solicitando el reconocimiento de la condición de refugiado, en comparación con sólo el 5.6\% de la población migrante que no se identifica como parte de la comunidad LGBTI (Hogar-Refugio para Personas Migrantes, La 72, 2017).

Esto permite pensar que, aunque el porcentaje de personas LGBTI que llegan a este albergue es menor en relación con el total de personas migrantes, sus razones de salida, el contexto del tránsito y una diversidad de nuevas producciones simbólicas que emergen en el desplazamiento de esta población hacen que las personas de ese colectivo tiendan a ser solicitantes de asilo en mayor medida que quienes no. Por lo tanto, se trata de un grupo de personas que permanecen por temporadas más largas que el resto de la población migrante en los lugares de tránsito, ya que los trámites de regularización obligan a no salir de la entidad federativa en donde se solicita dicho trámite. Esto los vuelve un grupo mayoritario que está considerando el territorio mexicano como una opción de llegada, solicitando el reconocimiento de la protección internacional.

Periódicus, Salvador, n. 12, v.1, nov.2019-abr.2020 - Revista de estudos indisciplinares em gêneros e sexualidades Publicação periódica vinculada ao Núcleo de Pesquisa NuCuS, da Universidade Federal da Bahia - UFBA ISSN: 2358-0844 - Endereço: http://www.portalseer.ufba.br/index.php/revistaperiodicus 
Pensar el flujo migratorio en tránsito desde Centroamérica hacia México implica tanto imaginar al territorio mexicano en sí mismo como una frontera en toda su extensión territorial, como dar cuenta de los costos que implica ese movimiento. Este desplazamiento es ubicado, generalmente, a partir del cruce de la línea geopolítica fronteriza en el sur del territorio mexicano y su continuo atravesamiento hacia el norte, con la intención de llegar a la siguiente frontera formal que divide México y Estados Unidos. Sin embargo, este tránsito, en muchos casos, no sucede de manera lineal y progresiva, sino con caminos de vuelta, con tiempos de espera y espacios nuevos que se producen con los cambios de ruta constantes.

México suele ser caracterizado como un país de origen, tránsito, destino y retorno de la migración internacional. El papel de México como territorio de tránsito se ha convertido, de manera creciente, en foco de atención para la academia, la política, los medios y la sociedad civil organizada (OIM, 2016). Sin embargo, el escenario actual de la migración regional plantea un nuevo reto que posiciona a México como un país de refugio. Este reto no es sólo en términos políticos de lo que implica la reconfiguración de las relaciones internacionales, ni tampoco sólo en términos formales para poder dar respuesta a una crisis humanitaria, sino que se extiende a un reto conceptual, que nos obliga a una revisión de las categorías migratorias con las que abordamos la investigación sobre las migraciones en la región.

Este nuevo escenario dibuja un territorio de tránsito/permanencia y obliga a desplazamientos conceptuales de muy diversos órdenes: por un lado, un disloque de la idea lineal y fija que investiga los desplazamientos migratorios a partir de los puntos de partida-tránsitollegada; también exige un desplazamiento en la manera de capturar las rutas migratorias en función de un tránsito versus una permanencia, así como nuevas formas de acercarnos a interrogar estas trayectorias. Consideramos que es indispensable conceptualizar dichos desplazamientos como procesos vitales en sí mismos y no sólo en tanto movimientos territoriales que se enmarcan en un periodo de tiempo al que llamamos "tránsito". Resultan trayectos vitales articulados con nuevos procesos de producción de vida, con marcas en los desplazamientos, en el territorio y en las adscripciones políticas, sociales, institucionales e identitarias. En estas trayectorias, además, identificamos la aparición de nuevos procesos que, simultáneamente, hacen emerger otros escenarios de precarización, así como de acceso a derechos.

De acuerdo con el más reciente informe de WOLA (2017), ha habido un marcado aumento en el número de migrantes solicitantes de asilo que piensan quedarse en México, en 
lugar de viajar a los Estados Unidos. Entre 2014 y 2016 hubo un aumento del $311 \%$ en las solicitudes de asilo en México. En los primeros tres meses de 2017, México había recibido más solicitudes de asilo que en todo 2015. De acuerdo con los datos de la Comisión Mexicana de Ayuda a Refugiados (COMAR), en el 2017 se recibieron 14.619 solicitudes de asilo, duplicándose en el 2018 con 29.600 solicitudes. En el corte de julio 2019, por su parte, se contabilizaron 38.983 solicitudes (COMAR, 2019).

Es importante mencionar que la Convención de 1951 sobre el Estatuto de Refugiados previó en su artículo $1^{\circ}$ cinco causales como los principales motivos para ser reconocido como refugiado. Entre estas causales no se incluyó el género. Sin embargo, tal omisión no ha impedido que tanto el Alto Comisionado de las Naciones Unidas para los Refugiados (ACNUR) como la legislación mexicana, hayan considerado el género como un factor determinante para el reconocimiento de esta condición (Observatorio de Protección Internacional de la IBERO, 2019).

Esto es relevante ya que las personas LGBTI son extremadamente vulnerables a la violencia y discriminación tanto en los contextos que obligan la salida como en los procesos de tránsito. En muchas partes del mundo las personas LGBTI experimentan graves abusos contra sus derechos humanos y otras formas de persecución debido a su orientación sexual y/o identidad de género. Durante 2015, la CIDH recibió información de amenazas y otras formas de persecución que tuvieron como resultado la migración forzada de personas LGBTI de Honduras, Guatemala, El Salvador y Nicaragua. La misma Corte expresa que los marcos internacionales en materia de asilo no han tomado con suficiente atención las circunstancias específicas de las personas LGBTI, lo que trae como consecuencia que no reciban protección internacional efectiva (CIDH, 2015).

La persecución de personas a causa de su orientación sexual y su identidad de género no es un fenómeno nuevo. Sin embargo, en los últimos años, un número cada vez mayor de solicitudes de asilo son presentadas por personas LGBTI en diversos países del mundo (ACNUR, 2008), lo que no necesariamente tendría que ser resultado de un aumento de casos. Esto puede responder a un fenómeno de mayor visibilización de esta población y a una mayor posibilidad de acceder a la figura de refugiado a raíz del desarrollo de recursos legales más incluyentes.

México tiene el segundo lugar por crímenes motivados por transfobia en Latinoamérica, sólo después de Brasil. Además, se estima que el $90 \%$ de los crímenes no son denunciados y, 
entre los que se denuncian, el factor común es la impunidad (Transgender Europe, 2017). Ambos países concentran el mayor número de crímenes en números absolutos. Estas posiciones cambian cuando estos crímenes se calculan en relación con la tasa poblacional, y es ahí que Centroamérica toma las primeras posiciones. Honduras es el país con más crímenes en el mundo contra personas trans*, reportados desde 2008 al 2017, mientras que el segundo lugar es para El Salvador (Transgender Europe, 2017). Estos datos se deben considerar dentro del contexto altamente violento que viven ambos países. El Triángulo Norte Centroamericano se ha posicionado como la región más violenta del mundo, a pesar de que en ninguno de los países existe un conflicto armado declarado. El informe sobre Desarrollo Humano para América Central 2009-2010 indica que el promedio total de la región centroamericana es de 32 homicidios por cada 100 mil habitantes, un porcentaje tres veces más alto que el promedio mundial (Villalobos, 2017).

Estos datos reflejan un panorama de violencia generalizada para la región conformada por Centroamérica y México, que afecta de manera específica a las poblaciones más vulnerables. Ser mujer trans* en El Salvador, Guatemala y Honduras es sinónimo de discriminación, vulnerabilidad, violencia y expulsión. Estas personas se encuentran frecuentemente expuestas a ataques de odio que suelen quedar impunes, con el agravante de que las investigaciones no identifican a las víctimas por su identidad de género, sino sólo por los genitales, por lo que los asesinatos de las personas trans* quedan generalmente fuera de las estadísticas oficiales. En este contexto, el desplazamiento de personas de la comunidad LGBTI en general y de personas trans*, en particular, se vuelve una opción frecuente.

\section{Condiciones del desplazamiento forzado trans*fronterizo}

La llegada de las mujeres trans* al albergue de La 72 se da como migrantes irregulares ${ }^{2}$, con un plan de viaje más bien contingente que se va elaborando a medida que se tiene que avanzar. Las mujeres trans* dijeron haber llegado a Tenosique con la idea de permanecer ahí por unos días y después seguir su camino hacia la Ciudad de México. Sin embargo, al atravesar la frontera mexicana y vivir los peligros que caracterizan esos caminos, conocer las historias trágicas de muchas personas migrantes, experimentar la potencia del tren y constatar la

\footnotetext{
${ }^{2}$ En el sentido de que la entrada al territorio mexicano no cumple con los lineamientos administrativos y legales que el Estado mexicano impone. 
existencia de bandas criminales al acecho, decidieron quedarse en el albergue por tiempo indefinido, hasta encontrar una estrategia de camino más segura.

Las historias de salida y tránsito de estas mujeres se dan en lo que aquí llamamos un desplazamiento forzado trans*fronterizo, que se va desarrollando de manera continua y va marcando la huida, en búsqueda de una supervivencia en la que su deseo y experiencia de género puedan ser expresados y la vida pueda ser habitada desde un lugar digno.

A partir de los relatos de las mujeres trans* entrevistadas, organizamos estas experiencias en tres momentos clave para comprender este desplazamiento. Primero, la relación del momento en que inicia su transitar de género y sexual con lo que aquí ubicamos como un exilio familiar. Posteriormente, están los itinerarios por los que comienza la vida en tránsito de estas mujeres, como escenarios de las huidas, donde se articulan la violencia, la transición de género y el desplazamiento. En un tercer momento, aparecen los lugares a los que se espera llegar, en tanto lugares geográficos, así como imaginarios relacionados con los terrenos afectivos, sexuales y del género.

\subsection{El exilio familiar}

El desplazamiento dentro de los países de origen de las personas trans* tiene su origen en un exilio que se da en los confines del hogar y la familia. Los momentos en que estas mujeres trans* se vieron interpeladas por su propio deseo y por la necesidad de expresarse con un género que no correspondía con los mandatos del género asignado en el nacimiento coincidieron con el mismo momento en que se vieron expulsadas de los espacios familiares. Así, el desplazamiento forzado de estas mujeres encuentra un quiebre anterior al movimiento que las hace dejar sus ciudades de origen y posteriormente sus países. Este exilio se da en el espacio del hogar y la familia, así como del barrio y la comunidad. Marcela dice al respecto:

\footnotetext{
"Yo vivía en Tegucigalpa, yo nací ahí. Creo que ahí es donde empezó mi transición. Porque de chico gay pasé a ser vestida, como travesti. Ya después de eso hubo muchos problemas... Cuando yo empecé mi transición, a los 16 años, en mi casa no me apoyaban. Me decían que ellos no querían culeros en la casa. Ni cuando era chico gay les gustaba, pero cuando me volví trans fue peor. Me decían que eso no lo iban a permitir, que yo tenía que ser el ejemplo para mis hermanas, porque era el hermano mayor. Me corrieron de la casa".
}

Periódicus, Salvador, n. 12, v.1, nov.2019-abr.2020 - Revista de estudos indisciplinares em gêneros e sexualidades Publicação periódica vinculada ao Núcleo de Pesquisa NuCuS, da Universidade Federal da Bahia - UFBA ISSN: 2358-0844 - Endereço: http://www.portalseer.ufba.br/index.php/revistaperiodicus 
Relatos como el de Marcela, mujer trans* hondureña de 19 años, muestran la manera más común en que se inauguran las historias de transición y de exilio de las mujeres trans*. Ser una mujer trans* en Honduras aparentemente se da sólo bajo la condición de una expulsión de los vínculos familiares y de los espacios comunitarios en los que crecieron. Hay una condena a una soledad que irá también definiendo los vínculos sociales en que se irá produciendo su vida afectiva posterior.

Cuando Marcela refiere que la familia no quiere culeros en la casa, está haciendo uso de una palabra que en Centroamérica señala la homosexualidad masculina. La transición de culero a trans*, como lo dice Marcela, es el parteaguas que resulta intolerable para las familias y que produce la expulsión del hogar. Se ponen en crisis las expectativas familiares sobre la masculinidad, como en este caso, las expectativas del hermano mayor que debe dar el ejemplo cumpliendo los mandatos masculinos relacionados con convertirse en el varón proveedor de la familia de origen y de la familia que después formará.

La homosexualidad aparece como una representación que resulta más soportable para el ámbito familiar, porque se le adscribe directamente a prácticas sexuales que pueden mantenerse en los confines de la vida privada. Sin embargo, el despliegue de una feminidad donde no se le espera, con los cambios subjetivos necesarios para performar un género que no corresponde con el asignado en el nacimiento y sus concomitantes expresiones en los espacios públicos, resulta insoportable para el orden de lo familiar.

En las historias de estas mujeres trans*, la violencia física ejercida por la familia es, muchas veces, un recurso de primera instancia. Esta violencia se extiende hasta alcanzar el exilio del hogar y se prolonga, en muchos casos, hasta el abandono permanente. Es común que ellas no tengan más contacto con sus familias desde el día que dejan sus casas.

Daniela dice: "Me vi sin mamá y sin papá, sin amigos y yo era lo que era y no podía regresar atrás, porque nunca iba a dejar de serlo”. Ella es una mujer trans* salvadoreña de 25 años, quien a lo largo de toda la entrevista constata el dolor por el abandono de sus padres. Daniela siente que si tuviera el apoyo de su familia la historia de su vida habría sido diferente, sin tener que transitar por espacios tan violentos, sin sentir la soledad que la acompaña en todos sus trayectos. Sin embargo, la soledad vivida resulta necesaria para poder ser lo que ella es, no hay vuelta atrás en su transición y por lo tanto no puede haber un regreso a los vínculos familiares que no tenían lugar para ella. 
El Transgender Law Center (2017) reconoce estas condiciones sociales de marginación que tienen que enfrentar las personas trans* como resultado de un abandono familiar. Esta organización señala que es frecuente que la violencia y las agresiones comiencen en sus familias o comunidades de origen. Se estima que $70 \%$ de mujeres trans* en Latinoamérica tienen que escapar o se ven expulsadas de sus hogares, lo que generalmente deriva en graves consecuencias emocionales, falta de oportunidades educativas, condiciones laborales precarias y falta de servicios de cuidado a la salud. Todas ellas eran menores de edad cuando fueron expulsadas de sus familias, por lo que las posibilidades de tener los recursos psíquicos, económicos y sociales necesarios para generar un autocuidado pueden ser escasas. La necesidad de buscar trabajos y condiciones materiales para su manutención también configuran otros caminos de vulnerabilidad.

No es suficiente salir de la casa, sino de todos aquellos espacios que conocieron antes de iniciar su transición. Entonces, la exclusión familiar, el abandono de los estudios, la falta de dinero para subsistir y la pugna por el deseo de transformarse en quienes ellas quieren ser hacen la combinación idónea para que el primer lugar de tránsito, en este exilio, sea el ejercicio del trabajo sexual en la vida nocturna de un barrio diferente o de una nueva ciudad dentro del país de origen.

Ubicar el trabajo sexual como primera opción de las mujeres trans* responde también a una lógica de exclusión generalizada, que va más allá de los confines de la familia y la comunidad cercana. Estas lógicas de exclusión se traducen, entre otras formas, en que hay ciertos espacios que pueden ser ocupados por ciertos cuerpos y otros que no. Para una persona trans* en Centroamérica, la forma más accesible para obtener recursos económicos y, al mismo tiempo, poder realizar una transición de género, es ocupar espacios igualmente precarios y marginales. Es preciso colocarse en los límites: las calles, la noche y el comercio sexual ilegal. La noche aparece como un escenario de condición para iniciar la transición: las primeras apariciones de las mujeres trans* con indumentaria femenina se realizan solamente en los espacios nocturnos.

La situación de estas mujeres trans* aparece marcada por una precariedad que se produce, por un lado, desde una ruptura con la normatividad que regula el género. Esta ruptura aparece desde una expresión de género que rompe con las normas de lo que se espera de la sexualidad masculina. Esto las convierte en blanco permanente de rechazo, discriminación, pobreza y condiciones sociales, que ponen muchos obstáculos para construir una vida más digna. 
Las vidas de estas mujeres trans* parecen posibles sólo en una condición de desplazamiento y huida permanente.

Por otro lado, esta expulsión de los vínculos primarios familiares, que proponemos leer desde un rompimiento con la normatividad del género, se piensa también como un rompimiento de un pacto vincular de dimensiones muy complejas, de las que también dichas normas del género participan, pero no lo agotan. Se trata entonces de un escenario de expulsión y precariedad que se articula con complejos procesos desde los que se inscriben los sujetos, en tanto sujetos sociales y atravesados psíquicamente por la diferencia sexual.

\subsection{Los escenarios de las huidas: violencia y discriminación}

Después de unos meses de llevar una vida como mujeres trans*, en las calles de sus países de origen y ejerciendo el trabajo sexual, los eventos de discriminación, amenazas, golpes o intimidaciones hacen insostenible la posibilidad de quedarse, si lo que quieren es vivir.

Para ellas la movilidad territorial y la transición de género son tránsitos que se articulan por medio de la violencia de manera dialéctica. Moverse supone la condición para poder llevar una transición de género lejos de sus comunidades de origen y lejos del rechazo familiar. Pero, al mismo tiempo, estas transiciones (la territorial y la de género) las ponen en nuevas posiciones de vulnerabilidad y producen nuevos escenarios violentos, por lo que se ven obligadas a desplazarse para salvaguardar la vida y continuar con el ideal de llevar a plenitud su transición de género.

En este camino de huida se superponen diversos ejes de análisis de la violencia padecida. Por un lado, los contextos de violencia que aparecen en los relatos de estas mujeres trans* tienen siempre como perpetradores a tres actores sociales principales: las pandillas (o mareros, como se les conoce en Centroamérica), la policía y otras mujeres trans*. El escenario de disputa y tensión con estos actores es siempre el trabajo sexual. Por otro lado, en estos mismos relatos, un denominador común en sus huidas es la experiencia de discriminación y acoso experimentado de manera general en los lugares cotidianos, que conlleva una expulsión de los espacios comunitarios y que termina confinando sus vínculos afectivos más profundos a relaciones solamente con otras mujeres trans*. La historia de Marcela ilustra muy claramente esta cadena entre las huidas, la violencia y la transición de género.

"El rechazo de mi familia me hizo salir de Tegucigalpa y me fui para San Pedro Sula. ¡En

San Pedro es donde ya me acepté como mujer! Pero entonces empezaron a haber muchos 
problemas con otras transexuales ahí. Entonces fue lo mismo, entre las mismas transexuales hay mucha envidia y violencia. Entonces ahí dije, mejor me voy de aquí antes de que me pase algo peor. Fue cuando me comuniqué con Nicole para irme a Guatemala, porque yo no quería más problemas, ni tener que meterme en cosas más graves de violencia en las calles.

Llegando a la Ciudad de Guatemala, gracias a Dios, Nicole me recibió con las manos abiertas. Y empecé a trabajar con ella en las calles, empecé a ganar mucho dinero, me volví más mujer.

En Guatemala seguí trabajando, pero las cosas en la calle iban cambiando. Las calles donde siempre trabajé ya estaban llenas de mareros. Enseguida empezaron a tomar el control de esas calles, pero como uno no les quería hacer caso, empezaron a llegar por las noches, directamente a tirotearnos. Mataron a muchas trans.

Había tiroteos en muchas calles donde trabajábamos, porque ninguna quería darles dinero. Ellos lo que querían era que les pagáramos por dejarnos estar ahí. Pero nosotras no queríamos darles nuestro dinero. Entonces ya teníamos encima a los mareros y la policía ¡imagínate! Había que irse de ahí. No quería más daño”.

Este relato es muy revelador para pensar cómo a partir del rechazo familiar dirigido a una experiencia que rompe con las identidades y corporalidades signadas por las fronteras sexuales, el desplazamiento es la única condición para ejercer una transición de género, pero, al mismo tiempo, esta transición produce nuevos escenarios violentos que necesariamente obligan a nuevos desplazamientos.

En este relato también es posible ubicar las tensiones que aparecen en el trabajo sexual entre mujeres trans*, mareros y policías. Se trata de tensiones que encuentran sus causas en complejos procesos históricos de la región -que no son objeto de este artículo -, pero que atraviesan las vidas que aquí se presentan. Niki lo expresaba de la siguiente forma:

"Tuve que huir de mi casa en Tegucigalpa. Me fui al centro y cambié de zona, me fui sola y ahí conocí a otras chicas trans y empecé a ejercer el comercio sexual. Empecé porque no tenía otra salida, sin empleo y sin poder estudiar. Me cobraban cuota dos chicas trans que se ocupaban de la calle. A ellas les daban órdenes las pandillas que hacían extorsión en la zona. Cuando no pude pagar la cuota me pegaron y me dieron un navajazo en la pierna 4 hombres y una trans. Me dio miedo que mi vida estuviera en riesgo y abandoné Honduras. Me fui a Guatemala y busqué la zona del comercio sexual. Una chica me llevó con la encargada, ella me dijo que me iba a cobrar 450 quetzales por entrar y 100 o 150 a 
la quincena, según la zona. Me ofreció llevarme a su casa y darme comida. Me dijo, yo te presto maquillaje, peluca y mañana sales a trabajar. Me fui con ella y me encerró en una casa de prostitución, donde estuve 6 meses. Desde el 18 de enero hasta el 23 de junio del 2016. Eso pasó porque me fui a Guatemala sin rumbo, sin conocer a nadie. Pero yo lo único que quería era irme de Honduras. En Guatemala me tuvieron secuestrada, extorsionándome, cobraban dinero por tener relaciones conmigo, me obligaban a robarles a los clientes. Pero una noche hubo un allanamiento en la zona 2 de Guatemala y fui rescatada. Nos regresaron para Honduras. Yo tuve que irme cuando me deportaron, desde la misma frontera, porque Honduras ya también era muy peligroso para mí. Me regresé a Ciudad de Guatemala esa misma noche y seguí con el comercio sexual, pero por mi parte. Como ya estaban presas las chicas trans que me secuestraron, yo ganaba mi dinero y era para mí. Así por 5 meses. Luego empezó una chica trans a cobrar 100 quetzales a la quincena, yo se los daba porque no me costaba y prefería estar ahí porque no tenía escapatoria, no podía regresar a mi país y no conocía otro lugar. Después empezaron a venir mareros en una moto y me pedían extorsión. Eran hermanos de la que me secuestró y me dijeron que iban a abrir la casa nuevamente y a las que no estuvieran adentro las iban a matar. Empezaron a dispararles a las trans de la calle y mataron a tres. Yo no tuve otra salida y me tuve que venir con dos amigas más a México. Estuve 15 días encerrada en mi casa hasta que decidí hacer esa salida. Pero no tenía opciones, tenía mucho miedo y se me terminaba el dinero".

Este denso fragmento del relato de Niki expone también la compleja realidad social, política y económica donde el trabajo sexual y el desplazamiento suceden de manera muy cercana a problemáticas relacionadas con la explotación sexual y la extorsión por parte del crimen organizado y las pandillas que controlan las calles en la región. Esta exposición a la violencia en la que se ejerce el trabajo sexual es frecuente, aunque resulta necesaria como forma de acceder a un ingreso económico que permita cierta independencia y las posibilidades de acceder a mejores condiciones materiales y simbólicas para la transición de género.

La situación de violencia y amenaza en estos países proviene también de autoridades, principalmente los cuerpos policíacos que patrullan las zonas del trabajo sexual. Daniela cuenta haber estado en una cárcel de El Salvador durante un año porque la levantó la policía por estar bebiendo con otras mujeres trans* y por atribuírsele cargos relacionados a un asesinato que no cometió. Ella dice que la cárcel fue una pesadilla, pero la salida de ahí, la relata como otro momento de terror, donde no se sentía segura ni en el cuarto donde vivía. Cuenta que un día caminando por el centro de San Salvador para buscar trabajo, los chicos de la Mara 18 le pusieron una pistola en la cabeza y le dijeron que sabían que ella vivía en el barrio de la Mara 
MS (Mara Salvatrucha), por lo que no querían volver a verla caminando por ahí. Decidió no volver a salir más de su casa, porque incluso la MS también la amenazó por haber estado en la cárcel compartiendo espacio con otros hombres de la pandilla contraria. Relata haber estado una semana encerrada, sin comer y sin poder dormir, sintiendo que se iba a volver loca. En esa época habían ya matado a casi todas las trans* que conocía. Un día desaparecieron a su hermano y por la noche ella decidió salir caminando escondida, para cruzar Guatemala y llegar a México. Este es el tipo de relato compartido entre estas mujeres trans*, cargado de miedo y de muchas muertes a su alrededor, que produce la certeza de que sus vidas ahí no durarán mucho tiempo. Daniela dice sobre la persecución vivida:

\begin{abstract}
"Yo anduve en la calle con amigas trans y me sentía bien porque ellas no me rechazaban. Pero en la calle me pasaron muchas cosas por andar con esas amigas, hasta que conocí la cárcel. Yo vivía en Usulután, un lugar muy famoso por ser peligrosísimo. Ahí mataron a todas mis amigas trans por andar en la calle y vestirse de mujeres. No se podía salir, ni siquiera ir a fiestas, las pandillas no lo permiten".
\end{abstract}

Experiencias como las del relato de Niki y Daniela podrían ser la cara más radical de los contextos de violencia que se viven en la región y que toman una forma particular en las vidas de las mujeres trans*. Daniela expresa que las pandillas tienen el control de las calles y entre los límites tácitos impuestos, no hay lugar para la experiencia trans*.

En sus experiencias de vida es posible identificar la grave problemática de violencia que azota a la región y que produce que miles de personas centroamericanas tengan que dejar sus lugares de origen escapando de esta violencia. Sin embargo, dentro de estos desplazamientos, los contextos de violencia para las mujeres trans* entran en relación directa con su expresión sexual y de género, articulados con los procesos de exclusión social de los que son víctimas desde edades muy tempranas y las relaciones de poder que se producen en el comercio sexual.

Niki, cuando habla sobre la experiencia de la discriminación en Tegucigalpa por su transición de género, dice:

\footnotetext{
"Me decían las personas yo te voy a hacer hombre, se burlaban de mí en las calles. Las chicas trans sufrimos doble discriminación, porque primero la sufrí cuando era chico gay, pero siendo trans sufro el doble. Pienso que es porque hay mucho machismo además de un status quo, porque la biblia dice hombre y mujer y no saben que si Dios quisiera eso no hubiéramos existido los LGBTI. Así como Dios ama una mujer hetero, ama a una chica trans".
} 
Niki lleva dos años en un estado de permanente huida. Habla de una experiencia de intensificación de discriminación a medida que su transición pasó de identificarse como chico gay a ser una mujer trans*. Esta discriminación se liga con creencias sobre lo que el género y la sexualidad deben ser, alimentadas por los discursos religiosos que ella termina integrando y resignificando de acuerdo con su expresión de género. Niki, como Marcela y Daniela, se ha visto desplazada continuamente teniendo que optar por nuevas ciudades, siempre en busca de un lugar donde pueda vivir sin sentirse amenazada.

Esta duplicación de la discriminación que Niki advierte se puede entender a partir de una articulación entre la matriz heteronormativa (Butler, 2001) y el binarismo de género. Ella dice que, si Dios ama a una chica "hetero", también ama a una chica trans*. En este argumento se solapan las posiciones de su deseo sexual con su posicionamiento trans* y, en su experiencia sobre la discriminación padecida, este solapamiento se experimenta como intensificación, como una doble discriminación.

Pensando estas experiencias que complejizan la violencia y discriminación en articulación con la transición de género y el desplazamiento forzado, podemos ubicar las aportaciones que consideran que el territorio cuerpo y el territorio espacial mantienen una interrelación de mutua constitución, en donde el performance de género no sólo se desplaza en el espacio, sino que se encarna en los cuerpos y también modifica el espacio en que éstos son actuados (Doan, 2010), por lo tanto, es necesario conceptualizar esta huida permanente de manera encarnada ¿De qué tipo de espacios se huye y qué tipo de espacios se buscan? ¿Qué modificaciones, en cuanto al cuerpo y el espacio, suceden en estos desplazamientos? ¿Qué producciones materiales van apareciendo en estos desplazamientos? Sostengamos estas preguntas que se articularán también con las discusiones más adelante.

Lo que interesa mostrar con esto es que los espacios geopolíticos no escapan de un ordenamiento sexual, que se configura en relación con un ordenamiento étnico y de clase; son también espacios sexualizados y marcados por este ordenamiento de diferencias. Los espacios, al mismo tiempo que establecen los parámetros de lo diferente, jerarquizan y producen lógicas de inclusión y exclusión legitimadas, lógicas de sentido y significación que (re)producen cuerpos y territorios que interactúan entre sí.

Las articulaciones interseccionales de estas mujeres son múltiples y se van reconfigurando permanentemente por una diversidad de actores sociales y relaciones de poder en 
las que estas disputas se producen. Esta relación entre discriminación-transición de géneroviolencia-desplazamiento parece no tener fin, se articula de manera compleja con las relaciones con otras mujeres trans*, con la violencia de las pandillas que controlan las calles de Honduras, El Salvador y Guatemala, así como con redes de tráfico de personas para el comercio sexual.

En los relatos de las trans* entrevistadas, todas coinciden en que cuando llegan a México es porque ya han pasado por varias ciudades de Honduras, El Salvador y Guatemala. Pero, a diferencia de la mayoría de las personas migrantes centroamericanas, el cruce por Guatemala no lo hacen en un día, con el objetivo de llegar cuanto antes a México o Estados Unidos para lograr una inserción laboral o un reencuentro familiar. En los casos de estas mujeres, las rutas se vuelven los territorios de tránsito permanente y son rutas que se configuran, en gran medida, por el trabajo sexual, el deseo de transición de género y los vínculos afectivos con otras mujeres trans*. Son rutas con otra temporalidad.

En el caso de las mujeres trans* el desplazamiento lo va definiendo la posibilidad de sobrevivir un día más en los lugares que se encuentren: cuando la vida queda expuesta al peligro, es momento de salir al siguiente destino. En este movimiento, la ruta se conforma de puntos geográficos que están íntimamente relacionados con el trabajo sexual y con la posibilidad de llegar a un lugar con otras mujeres trans*. Además, el dinero que permite costear estos viajes proviene en su totalidad de los ingresos de este trabajo y por lo tanto tiene sus límites, se va terminando con el desplazamiento y vuelve necesario detenerse en nuevos puntos para conseguir cantidades que permitan continuar con el viaje.

El trabajo sexual en las calles y la vida de noche son los espacios en los que la experiencia trans* va encontrando posibilidades de expresión. Ellas pueden vestirse como mujeres, maquillarse, usar tacones y usar su cuerpo feminizado para obtener ingresos que serán invertidos en ese mismo cuerpo, con el objetivo de lograr una expresión de género deseada. Los ingresos del trabajo sexual se utilizan como inversión para realizar procesos de estetización y de imagen que brindan un cierto estatus en las calles del comercio sexual, lo que se traduce en más clientes, más trabajo y mejores ingresos, pero, al mismo tiempo, se traduce en un cuerpo más deseado por ellas mismas, una imagen de mujer imaginada y buscada.

Aparece una relación íntima entre la transición de género, el trabajo sexual y el desplazamiento. En sus relatos, el comercio sexual se vuelve una actividad indispensable para transitar por la experiencia trans*, debido a la misma marginalidad a la que está sujeta la 
aparición en el espacio público de las trans*, pero también porque permite construir una vivencia singular femenina de lo trans*. En los casos de las mujeres trans* entrevistadas, la posibilidad de movilidad migratoria no habría sido posible sin las posibilidades económicas del trabajo sexual realizado desde sus países de origen.

Para las mujeres trans* hondureñas y salvadoreñas, Guatemala ya es un territorio menos hostil (a ratos), pero donde tampoco se puede permanecer mucho tiempo. Guatemala aparece como una opción para llevar a cabo una transición de género más plena que, por lo menos, salga de los confines de la noche y del trabajo sexual. Como ellas dicen, "en Guatemala pueden ver el día", caminar en las calles y realizar actividades cotidianas vestidas como mujeres. Guatemala también se vuelve un lugar con un tránsito particular, pues muchas de ellas no necesariamente se mueven en dirección al norte. Debido a que la frontera sur entre México y Guatemala es la primera frontera formal que tienen que cruzar de manera indocumentada, es ahí donde aparece el primer gran muro que hace que muchas de ellas decidan quedarse del lado guatemalteco por temporadas largas, yendo y viniendo entre Guatemala, Honduras y El Salvador. Sin embargo, insisten, esto no es sostenible por mucho tiempo. Honduras y El Salvador "son lugares para salir y no volver, si lo que quieres es conservar tu vida". Guatemala puede ofrecer un lugar intermedio, que permite ejercer el trabajo sexual, pero, además, permite otro tipo de tránsito: pasar de ser mujeres sólo durante la noche para comenzar a ser mujeres durante el día y en su vida cotidiana. Marcela menciona lo siguiente en relación con este circuito:

\footnotetext{
“Guatemala no es como en Honduras, aún hay espacios que las maras no controlan pues apenas están peleándose las calles y entonces es más fácil trabajar. Eso en Honduras ya está más claro, ahí no puedes hacer nada sin que los mareros lo sepan. No puedes estar ahí sin que ellos te molesten. Tienen mucho poder. Pero en Guatemala es que la gente no es tan violenta con una en la calle, como en Honduras.
}

Lo que pasa, además, es que en Guatemala es más normal ver a una chica trans en la calle y de día. Ahí hay chicas operadas y ya empieza a ser normal. En Honduras no salen de lo acostumbrado, pero yo creo que como Guatemala, México y EUA están cerca y ya son lugares donde uno puede adquirir operaciones y todo, pues las trans guatemaltecas suben a México a operarse y regresan a Guatemala. Así la gente lo empieza a ver normal, se va acostumbrando. Pero cuando una llega a Honduras operada eso ya no es normal. Entonces empieza el bullying y la discriminación y más violencia.

Yo en Guatemala me empecé a maquillar y permanecía todo el día como trans, hasta dormía con shortcitos y ya no dormía con buzos, me sentía mujer. Antes sólo era de 
noche y para trabajar en el comercio sexual y todos te relacionan con eso, como prostituta y nada más. Cuando lo haces de día es porque ya lo haces para sentirte bien, que ya eres una mujer a cualquier lado al que vas. No sólo como trabajadora sexual."

Marcela ubica a México y Estados Unidos como una región norte donde hay más posibilidades para acceder a implantes, hormonas y cirugías. Ella identifica que en Guatemala, al estar más cerca de esta región, ya experimenta cambios en la vida cotidiana que pueden ser más favorables para vivir con menos discriminación, porque siente que al ir "subiendo" hacia México, va transitando también desde un espacio de anormalidad a uno de normalidad. Sin embargo, son espacios que no escapan del todo al control de las pandillas, tanto mexicanas como centroamericanas, lo que ha empezado ya a configurar un panorama de violencia recrudecido que sigue acompañando ese transitar.

En todas las conversaciones con estas mujeres, se habla de la palabra discriminación como termómetro para la experiencia de habitar un lugar. La vivencia de discriminación en los espacios públicos también se articula con una mayor o menor dificultad para llevar a cabo una transición de género más allá de los espacios violentos que ofrece el trabajo sexual. Ellas saben que no existe el lugar en que no haya discriminación para ellas, pero buscan un lugar donde no se les atribuya una anormalidad, no se ponga en riesgo su vida y tengan acceso a tratamientos para modificar su cuerpo.

En Guatemala las tensiones en el trabajo sexual se relacionan con las redes de explotación sexual que están también controladas por mujeres trans* que ellas mismas identifican como "trans* viejas", es decir, mujeres trans* que por su edad ya no pueden vivir del trabajo sexual porque se les considera que ya no son un "producto deseado", por lo que algunas comienzan a vivir de la explotación de las más jóvenes. Son quienes tienen el control sobre las calles y los cuerpos de las mujeres trans* que comienzan en el trabajo sexual. Este control se puede ver intensificado en el caso de que se trate mujeres trans* migrantes provenientes de Honduras o El Salvador, ya que resultan más deseadas en el mercado del trabajo sexual de Guatemala y, además, pueden ser las más vulnerables para la explotación por la falta de redes y de cuidados en ese país.

En las tensiones entre estas redes de explotación y las pandillas es que las mujeres trans* más jóvenes y extranjeras terminan una vez más desplazadas por razones de violencia. En este nuevo desplazamiento el camino empieza a empujar hacia México porque es común que ya haya 
otras amigas, también mujeres trans*, que llegaron a la Ciudad de México. Esto hace un escenario posible para que aquellas que se ven en una situación de miedo decidan de un día para otro moverse y cruzar la primera frontera formal hacia el norte.

\subsection{Los lugares a los que se espera llegar}

Hasta el momento es posible identificar cómo en estos movimientos de huida se empieza a configurar un proyecto de transición de género que se superpone con las condiciones económicas de la región México-Centroamérica. El Salvador, Honduras, Guatemala y México aparecen, en el discurso de estas mujeres, como territorios envueltos en un sistema económico y social que, a medida que se van a acercando al norte, permiten más posibilidades de modificación corporal, mejores ingresos en el trabajo sexual y una mayor aceptación de su existencia como personas trans*, que ellas mismas traducen en menor discriminación. Todo esto va haciendo más atractiva la huida de los países de origen y llevando un desplazamiento que las acerque, cada vez más, a la Ciudad de México, ciudad que aparece como lugar idealizado, que posibilita operaciones, hormonización, intervenciones en el cuerpo más baratas y seguras, pero también una vida menos amenazada por la violencia y la discriminación.

En este tránsito de huidas permanentes existen dos grandes motivos que se entrelazan hacia un ideal: la llegada a la Ciudad de México y la llegada a una experiencia femenina total. Así como existe un lugar geográfico idealizado que se pretende alcanzar para escapar de los territorios de violencia y discriminación, también existe una pugna del deseo que se abre camino con un ideal de la búsqueda de hacerse mujer.

Con esto es necesario sostener el argumento de un desplazamiento forzado, pero que empuja con fuerza desde dos direcciones, es decir, aparece complejamente forzado. Por un lado, la salida y el país de origen expulsa porque amenaza la existencia; por el otro, hay una potencia vital, pulsional y deseante que exige la búsqueda de otros espacios subjetivos y sociales que permitan no sólo la supervivencia, sino una existencia vital que sólo es posible con la transición de género.

En este escenario, la capital mexicana es una gran desconocida para estas mujeres trans*, pero aparece muy idealizada en sus discursos, como una ciudad donde podrán realizar todos sus sueños. Este ideal de realización que ofrece la Ciudad de México parece estar muy alimentado por los relatos de otras trans* que ya están ahí y con quienes tienen contacto. 
En los relatos de las mujeres trans* que han pasado por Guatemala, se ubica ya un contacto con un espacio con menor discriminación, mayor aceptación social y más posibilidades de hormonización y estetización del cuerpo, lo que en sus vidas se traduce en ascenso social y económico entre sus pares y una mayor inversión en su imagen y su cuerpo, es decir, una nueva experiencia plena de transición. Todos estos elementos resultan importantes para tener una mayor aceptación de la misma experiencia que les ha costado el rechazo familiar y la expulsión de todos los espacios habitados. Experimentan la sensación de ser más bellas y con mayores recursos simbólicos y materiales para solventar su vida de forma independiente. En este sentido, el ideal construido respecto a la Ciudad de México se sostiene con la expectativa de que los cambios favorables experimentados en Guatemala se potenciarán con la llegada allí, de tal manera que puedan alcanzar todo lo que han soñado. Marcela lo explica así:

\begin{abstract}
“A Honduras yo no quiero volver, pero a Guatemala sí, porque hay algunas opciones de hormonas y operaciones. En Honduras no hay nada de eso. En Guatemala puede ser un poco caro, pero se consigue. Ponerte los pechos te cuesta unos 17 mil o 18 mil quetzales ${ }^{3}$. Eso lo puedo ahorrar como en un año, yo creo. En Honduras por algún lado debe haber, pero deben ser muy caras y para muy poca gente, pero además ahí no te quedan bien las operaciones. En cambio, en el D.F. por lo que sé, te las hacen en todos lados y es más común que siempre queden bien. Además, ganás más dinero. ¡Incluso algunas ya se han casado! Entonces todo eso a mí me emociona, me incita a irme, porque yo quiero pasar todo eso".
\end{abstract}

En el caso de Marcela es claro que los motivos que la hacen buscar la Ciudad de México como destino son las posibilidades de intervenir su cuerpo con mejores resultados, en un contexto donde tendrá mejores ingresos para pagar mejores intervenciones y donde además pueda cumplir fantasías afectivas relacionadas con ideales de género tradicionales.

Niki, cuando piensa el lugar al que espera llegar habla de una búsqueda entre fantasía y realidad:

\begin{abstract}
"Quiero llegar al DF y estudiar periodismo. Quiero ser una periodista trans y demostrar que una mujer o un hombre tienen los mismos derechos y posibilidades que una chica trans. Yo quiero abrir una puerta y entrar.
\end{abstract}

Me veo casada. Detrás de una cámara de tv con micrófono, dando reportajes, arreglada, con el pelo planchado y la ropa adecuada a la ocasión. Yo sólo me hormonicé por tres

\footnotetext{
${ }^{3}$ De acuerdo al tipo de cambio del 3 de febrero 2020, 1 quetzal son US\$ 0.13. Los 17000 y 18000 quetzales serían entre US\$2 222 y US\$2 353 
meses en Guatemala, pero el efecto no me gustó porque me hizo subir de peso. Me hizo cambios que no me gustaron así que paré y traté de recuperar lo que yo era. No pienso en operaciones, quizás sólo implantes de pechos.

La ciudad en la que quiero vivir es una donde no se me etiquete como una chica trans, que se me mire más allá de eso, la ciudad que me gustaría no existe en el mundo. Sería con calles de cristal, brillante y hermosa, donde se me apoye, donde haya oportunidad de empleo, donde pueda ser feliz, que me pueda casar, que pueda adoptar niños. Me gustaría formar una familia. Pero no una familia como todas las personas la piensan, sino como una comunidad, que me pueda llevar con todos, que nos ayudemos. No quiero llamarle comunidad sino familia, tal vez no se pueda lograr todo, pero espero que algunas cosas sí".

Niki afirma que la ciudad que busca no existe en el mundo, habla de una fantasía que no corresponde con ningún lugar conocido, ni con un lugar por conocer, pero eso no le impide desearlo. Ella quiere demostrar que un hombre y una mujer tienen los mismos derechos que una mujer trans* y con esto poder dejar de ser ubicada sólo desde lo trans*, es decir, que la mirada hacia ella sea desde otros lugares de reconocimiento social. ¿Será esa puerta a la que quiere entrar? El discurso de Niki sobre su experiencia de género parece apuntar a un espacio al que aún no puede entrar, donde quizás lo trans* no sea una categoría que identifique la totalidad de su experiencia deseante, pero que funcione como identidad política que permita demostrar un lugar de igualdad de derechos. Podemos leer una intención de lograr sus objetivos visibilizando una identidad trans* sin que esto la atrape en un lugar identitario fijo y totalizante.

En el caso de Niki se reconoce una motivación que escapa de las concepciones tradicionales de la familia, puesto que dice que no la piensa como la mayoría de las personas pensarían estos vínculos. Incluso prefiere no llamar a ese ideal como familia sino como comunidad. De alguna manera esta comunidad es parte del deseo que todas buscan al expresar vivir en espacios sociales sin discriminación. Niki ahí es donde quiere encontrar y restituir los vínculos familiares que no ha tenido, desde lo común y desde los espacios próximos de las personas con las que comparte su cotidiano. Para ella, estar en La 72, de alguna manera se asemejaba a la posibilidad de experimentar vínculos afectivos comunitarios, pero los vivía de manera transitoria, ya que sabía que el albergue no puede darle las posibilidades económicas, laborales y de reconocimiento social a las que aspira.

Con este doble ideal sobre llegar a la Ciudad de México y llegar a un lugar del género donde se espera una fantasía de vivirse como mujeres de manera completa, en este trabajo se 
piensa en términos de fantasías que funcionan en tanto búsqueda y en tanto trabajo de producción de estrategias para una vida deseada fuera de los espacios de la violencia. Pero, en relación con el lugar de mujer al que se espera llegar, consideramos que necesariamente entrará en tensión con una incompletud intrínseca de la misma categoría de "mujer". Esta fantasía sostiene y echa a andar el deseo desde una totalidad que se posterga de manera permanente: el ser mujer-mujer no es una entidad que exista como estado permanente, no es un lugar de llegada, pero justamente en este desplazamiento, por lo inabarcable de la categoría, es que se va produciendo la experiencia de estar haciéndose mujer. Butler (2001) apuesta a entender el género como conjunto abierto que permite múltiples discrepancias y coincidencias sin obediencia a un fin último y normativo. Sin embargo, con las trayectorias revisadas sí aparece la experiencia de alcanzar un fin último, que muchas veces aparece también de forma normativa, pero en su búsqueda se desplaza.

En esta aspiración de la fantasía sobre los lugares de llegada del género, es que puede entenderse la doble disposición de los mandatos del género como frontera y multitud. Como Pons Rabasa (2016) afirma, el género es frontera que limita al sujeto, pero a la vez es multitud de posibilidades, experiencias que, en su consecución, podrían llegar incluso a transformarlo.

Estas motivaciones de la migración y la diversidad sexual se relacionan generalmente con un movimiento que permite escapar de condiciones represivas de prácticas sexuales no heteronormativas, así como buscar mejores oportunidades laborales y de sociabilidad que son imaginadas en países donde existen marcos legales de reconocimiento y protección de derechos para personas gays, lesbianas y/o homosexuales (Pichardo, 2003).

Como herramienta analítica de las particularidades de estos desplazamientos conviene retomar el concepto "migración trans" de Vartabedian Cabral (2012), usado en el marco de la migración hacia España de mujeres travestis brasileñas. Este concepto nos sirve para pensar la particularidad de estos procesos migratorios cuando los términos "migración sexual" y “migración queer" resultan limitados para comprender la complejidad del fenómeno. Entender la "migración trans*" implica considerar que las personas trans* no sólo migran para sentirse más libres y respetadas para poder expresar así sus sexualidades e identidades de género en plenitud, sino que están cruzando unas fronteras espaciales transnacionales, al mismo tiempo que construyen su propia identidad. 
Vartabedian Cabral (2012) define a la migración trans* como una migración que se busca como fin para vivir una sexualidad y una expresión identitaria más amplia, al mismo tiempo que se buscan los medios económicos y sociales para una vida con más recursos simbólicos y con mayores posibilidades de intervenir el cuerpo para alcanzar estándares estéticos deseados. Sin embargo, lo que resulta interesante de este concepto es que para la autora el proceso migratorio trans* es algo más que un viaje meramente económico, de intervención corporal o con fines de encontrar una plenitud de expresión, sino que es un viaje que hace, en sí mismo, el proceso de la construcción identitaria trans*.

En el contexto de la migración trans* centroamericana en México, es importante retomar este concepto de migración trans* de manera crítica, visibilizando las particularidades que emergen en el desplazamiento forzado que se vive en Centroamérica, con otras particularidades más allá de un viaje deseado. En este sentido, la pregunta sería: ¿cómo articular los conceptos de desplazamiento forzado y el concepto de migración trans*? La propuesta aquí es utilizar el término de "desplazamiento forzado trans*fronterizo" con la idea de dar cuenta de esta reconfiguración que incluye el carácter forzado más allá de las fronteras internas del país y el foco en cómo ese mismo desplazamiento materializa, interpela y produce singularidades en la experiencia trans*.

Además, la intención de ubicar que se trata de un desplazamiento que traspasa los límites internos y adquiere dimensiones internacionales interesa para dar cuenta de dos cuestiones: por un lado, permite reconocer los nuevos estatutos que aparecen en las configuraciones jurídicas, políticas y subjetivas más allá de las fronteras nacionales y, por otro lado, señala el corrimiento que se produce de la figura de desplazado a la de refugiado. Así, también, permite dar cuenta de las posiciones que se cruzan más allá de las fronteras del género y las identidades sexuales esencializadas desde un solo lugar de partida y un solo lugar de llegada, sin considerar los espacios de transición como lugares de producción en sí mismos.

\section{De migrantes irregulares al reconocimiento de la Condición de}

\section{Refugio}

Retomando la pregunta de ¿cómo se ha desplazado en las personas trans* la experiencia de un tránsito migratorio a la demanda de un reconocimiento de la condición de refugiadas? es importante advertir que en estas trayectorias de vida, con sus espacios y tiempos en el tránsito, 
subyacen múltiples desplazamientos (territoriales, institucionales, identitarios, etc.). El tránsito en sí mismo produce formas de espera que conllevan cambios, también, en la configuración de los sujetos mismos que lo experimentan. Estas trayectorias no pueden ponerse en la disyuntiva del tránsito versus permanencia, sino que necesitan pensarse como emergencia de singularidades territoriales que escapan de la territorialidad administrativa de las fronteras.

Pensar un territorio de tránsito/permanencia, bajo la figura jurídica del reconocimiento de la condición de refugiado, permite dar cuenta de que el acceso a la información sobre este derecho y la conciencia de la necesidad de protección internacional han producido nuevos proyectos para muchas mujeres trans* que, en esta huida, deciden solicitar asilo en México. Esto les exige posicionarse como sujetos de derechos, así como víctimas de un desplazamiento forzado trans*nacional que se relaciona directamente con su posición sexual y de género.

Los atravesamientos de las fronteras territoriales dejan marcas en las vidas de quienes los realizan. Sin embargo, además de la frontera formal de los Estados, la frontera, en su multiplicación interna, deviene en expresiones de violencia, discriminación y marginación, de manera específica e intensificada para las personas trans* que vienen de Centroamérica. Estas fronteras internas se vuelven un "sistema de esclusas que fija a determinados hombres y determinadas mujeres a ciertos espacios sociales y laborales" (Malo, 2006). En el caso de los cuerpos que no corresponden con la imagen normada de un hombre o de una mujer, se vuelven cuerpos que incomodan en el espacio, porque no se sabe qué lugar darles. De igual forma, los cuerpos migrantes, en tanto cuerpos que vienen "de afuera", se les identifica también como cuerpos fuera de lugar.

El concepto de fronteras internas se vincula con el de interseccionalidad, generando procesos de inclusión/exclusión complejos y no estáticos. Brah (2013) define la interseccionalidad como los efectos irreductibles, variados y variables que resultan cuando múltiples ejes de diferencia (económica, política, racial, cultural, psíquica, subjetiva y experiencial) se intersecan en contextos históricos específicos. En esta discusión argumentamos que los procesos de producción y de formación de sujetos aquí analizados corresponden a un contexto social e histórico complejo que configura escenarios en movimiento constante. Las personas trans* en su desplazamiento forzado trans*fronterizo muestran diversas configuraciones de interseccionalidad, en tanto articulaciones de diversos procesos subjetivos y 
sociales. Dichas configuraciones interseccionales son entendidas como los procesos de la experiencia migratoria trans* en sí misma.

Brah (2013) entiende la experiencia como un proceso de significación, una práctica de dar sentido simbólica y narrativamente. La experiencia no le sucede a un sujeto ya constituido que experimenta, sino que es el lugar de la formación del sujeto, el sujeto que interpela es interpelado. En esta experiencia, los procesos de corporización, en los que se incluye el funcionamiento de la psique, son cruciales. Las personas son producto de una amalgama de posiciones subjetivas que se configuran a través de funcionamientos de la psique desordenados y precarios, en un exceso interseccional de experiencia.

En este sentido, el análisis sobre las repolitizaciones que conllevan el atravesamiento de las fronteras será parte de esas mismas experiencias interseccionales que se producen en un momento particular del tránsito de estas personas. Por lo tanto, cuando hablamos de experiencias migratorias no sólo nos referimos a sus desplazamientos espaciales, sino también a sus tránsitos en el orden del cuerpo, de los entornos sociales, las formas de nombrarse y de apropiarse categorías identitarias como puede ser el término trans* o el de refugiada.

En los tránsitos de las mujeres trans* también aparecen movimientos erráticos y heterotópicos constituidos a través del deseo y la agencia, que atraviesan múltiples fronteras y configuraciones temporales, sociales y sexuales (Cotten, 2012). No se trata de un proceso migratorio con un viaje de "ida", lineal y teleológico con un proyecto que estabilice los puntos de salida y de llegada.

Para Vartabedian Cabral (2012) el empleo de la metáfora del viaje es adecuado para comprender estas experiencias migratorias. Sin embargo, las personas trans* no llegan a ningún lugar seguro y estable como meta última. La experiencia trans* requiere un proceso de continuo trabajo y dedicación que nunca tiene un fin. En consecuencia, más que el destino al que se aspira llegar, la experiencia de transformación se da en estos tránsitos constantes y permanentes.

En este caso, el desplazamiento se sostiene por una búsqueda de un lugar donde sus vidas no sean amenazadas por la impugnación de los mandatos sexuales que representa su transición en el cuerpo, el deseo y la identidad, así como por una necesidad de búsqueda de posibilidades de transformación que les permitan transitar también sobre el ideal de mujer que se busca. El tránsito en el territorio mexicano, así como el transitar sexual, se da de manera singular y 
permanente, ya que así como no existe un lugar de inclusión total, no existe tampoco un lugar de mujer al que se llegue, de una vez y para siempre. Se busca un lugar idealizado que ellas mismas saben que no existe, es decir, un lugar donde puedan vivir sin discriminación, sin violencia y con acceso pleno a derechos; así como también buscan un lugar idealizado en las posiciones sexuales, donde se puedan volver mujeres en un sentido completo, lo cual tampoco existe para nadie. Las mujeres trans* esperan en territorios donde las políticas sexuales internacionales han puesto la bandera de la diversidad sexual, dan forman y producen una visibilidad nueva para sus vidas. Sin embargo, al mismo tiempo, transitan caminos que las van llevando permanentemente a un nuevo escenario de exclusión y violencia.

Como parte de esta multiplicación de discursos que aparecen en el tránsito, se encuentra el acceso a la información sobre la posibilidad de solicitar asilo en México. Esto ha venido a dibujar otras trayectorias que se articulan con nuevos discursos sobre la diversidad sexual y los derechos humanos; con instituciones estatales, actores de la sociedad civil y organismos internacionales. Además, plantea nuevos tiempos de espera prolongados en diversos espacios migratorios. La vida del tránsito se vuelve permanencia en espera de resoluciones estatales y con esto, se producen nuevos procesos donde se repolitizan ciertas identidades, cuerpos y adscripciones a colectivos de manera singular. A continuación, explicaremos el análisis de este argumento a través de dos experiencias puntuales que usaremos como metáfora para pensar estos desplazamientos identitarios.

\subsection{El módulo LGBTI de la 72}

El módulo LGBTI corresponde a uno de los dormitorios que se ubican como módulos de grupos vulnerables dentro del albergue. Los otros dos son el módulo de menores no acompañados y el módulo de mujeres. El módulo LGBTI se ubica dentro de La 72, en un edificio de dos plantas pintado con un llamativo color rosa. Desde su balcón cuelga la bandera de la diversidad sexual con los colores del arcoíris. Dentro de cada cuarto hay un letrero que dice: "El respeto al cuerpo ajeno es la paz", realizado por otras personas que han pasado por esos dormitorios.

Cuando una persona llega a La 72, generalmente, no sabe a qué tipo de albergue ha llegado y es muy probable que, si se trata de personas de la comunidad LGBTI, intenten esconder esto hasta confirmar que se trata de un lugar seguro. En la experiencia del trabajo de campo se constató que el momento de llegada de las mujeres trans* al albergue tiene un valor significativo, pues después de atravesar la frontera de México y Guatemala caminando, para internarse en el territorio 
de manera clandestina, el miedo a la posibilidad de ser rechazadas de cualquier espacio se intensifica.

Una de las mujeres trans* entrevistada cuenta que cuando llegó a la casa y pasó por el registro de datos inicial, se presentó con su nombre femenino, pero tuvo que dar su nombre legal ya que le pidieron una credencial para identificarse. Sin embargo, dijo sentirse aliviada cuando después de ver su identificación, la persona que hacía el registro continuó llamándola por su nombre femenino. Otra dice que decidió esperar afuera, después de pedir a sus compañeros de viaje que preguntaran si ella podía entrar al albergue vestida de mujer.

En esta llegada, las mujeres trans* tampoco saben que el albergue ofrece un dormitorio para personas de la comunidad LGBTI. Para muchas, la llegada al albergue fue también la primera vez que escucharon las siglas LGBTI o que se vieron nombradas como mujeres trans*, ya que antes simplemente se identificaban como culeros, término que engloba a los hombres gays, trans* o cualquier expresión de género y sexual que trasgreda los mandatos de la masculinidad. Algunas de ellas ni siquiera conocían la bandera de la diversidad sexual, ni la bandera trans*, símbolos que en el albergue están muy presentes, decorando muros o colgando desde balcones. Ellas mencionaban que cuando llegaron al albergue, la primera gran sorpresa fue que les mostraron las banderas y les explicaron lo que representaban. Esto les provocó algo nuevo, una sensación de formar parte de algo que es motivo de orgullo y que nunca habían experimentado así.

Los relatos sobre las llegadas de las mujeres trans* al albergue coinciden tanto en las condiciones de salida marcadas por la expulsión, así como con los peligros, el miedo y la desconfianza al atravesar la frontera mexicana en clandestinidad $\mathrm{y}$, finalmente, con un desconocimiento de la existencia de un espacio identitario llamado LGBTI con implicaciones simbólicas contrarias al rechazo experimentado, y con implicaciones materiales que se traducían en una habitación propia, con la promesa de un lugar seguro y de cuidados.

Debido a esta sensación de clandestinidad, miedo y vergüenza que se intensifica con el cruce de la zona fronteriza, así como el acceso de información sobre la figura del reconocimiento de la condición de refugiado, todas ellas habían optado por iniciar un proceso de solicitud de este reconocimiento, con el fin de poder transitar el territorio sin el miedo a ser detenidas y/o deportadas. Con esto aparecen nuevas formas de espera en los lugares de tránsito, se prolongan los tiempos administrativos del Estado que tiene repercusiones en los cuerpos, en los proceso de hormonización, en la falta de recursos económicos para "producirse" como mujeres, pero además 
aparecen nuevas transformaciones para relacionarse con los espacios del albergue que habitan por temporadas largas: aparecen nuevos lugares de poder y de toma de decisiones frente al resto de los migrantes; así como nuevas figuras identitarias en sus posicionamientos. Las siglas y símbolos de la comunidad LGBTI, la identidad de mujer trans* que va tomando más nitidez en su contexto social y el paso de migrante indocumentada a refugiada, reconfiguran nuevas relaciones con su propio transitar sexual y de género, así como en las relaciones sociales e institucionales que establecen.

\subsection{La "palapa del producto": transición y traducción}

Durante el periodo de tiempo en que se realizó la investigación, el módulo LGBTI estuvo ocupado de manera permanente tanto por mujeres trans* como hombres gays provenientes de Honduras, El Salvador y Guatemala. Debido a que este trabajo de campo se realizó en un solo viaje, ese grupo de personas fueron las únicas que se llegó a conocer en ese albergue.

Las personas del módulo LGBTI, al mismo tiempo que conformaban este módulo, producían marcas singulares de reapropiación de los discursos sobre la diversidad sexual que circulaban en dicho espacio. Esto resulta fundamental ya que ubicamos dos espacios con una relevancia etnográfica propia y que, aunque son diferentes, están produciéndose al mismo tiempo en el encuentro de un cierto grupo de personas con el soporte formal de un dispositivo de saberes y poderes sobre la sexualidad que, en este caso, es el espacio de La 72.

Estos dos espacios son, por un lado, el módulo LGBTI delimitado por la organización del albergue, produciendo discursos propios de una identidad política reconocida, organizando el espacio con un reglamento interno, definiéndolo con una bandera que cuelga como emblema del territorio, practicando un procedimiento para el ingreso y un acompañamiento particular para apoyar en los procesos de transición sexual, así como en la solicitud del reconocimiento de la condición de refugio. Por otro lado, ubicamos otro espacio que se inscribe en el anterior, pero que va más allá de él y tiene otras dimensiones. Este espacio es la "Palapa ${ }^{4}$ del Producto" que tiene efectos más allá de la identidad del módulo LGBTI, con producciones contingentes, inesperadas e inconmensurables. Estos efectos se dan en los espacios sociales de las personas que usan el módulo, en esa dimensión del deseo que necesariamente se da en el estar con otros. En ese sentido, la "Palapa del Producto" está más cerca de la experiencia singular de las personas

${ }^{4}$ Una palapa es una vivienda al aire libre con techo formado con palmas secas y soportes de madera de palma. Periódicus, Salvador, n. 12, v.1, nov.2019-abr.2020 - Revista de estudos indisciplinares em gêneros e sexualidades Publicação periódica vinculada ao Núcleo de Pesquisa NuCuS, da Universidade Federal da Bahia - UFBA ISSN: 2358-0844 - Endereço: http://www.portalseer.ufba.br/index.php/revistaperiodicus 
en su negociación con las identidades políticas que representan a esas personas que lo que se llamaba el Módulo LGBTI. El surgimiento del nombre de la "Palapa del Producto" ocurrió de forma espontánea y a manera de una apropiación territorial. La palapa que las personas del módulo LGBTI ocupaban para descansar, comer y pasar el tiempo libre se encontraba en un área de uso común dentro de La 72. Este espacio, a pesar de ser un espacio común (o justamente por eso), estaba notoriamente marcado por la presencia masculina.

En una ocasión, mientras varias personas almorzábamos sentadas en una de las palapas con el grupo de las mujeres trans*, en medio del alboroto de las risas y los gritos, se escuchó a una de ellas decir que la palapa más divertida para sentarse a comer era la "Palapa del Producto". El resto de las trans* rieron a carcajadas e hicieron un bullicio, llamando la atención de todas las personas que comían en el albergue. Los grupos de personas migrantes alrededor observaron en silencio con una mirada seria y reprobatoria. Las trans* celebraron a gritos el nuevo nombre de la palapa. Frente a la pregunta de por qué "del Producto", una de las trans* contestó con un gesto de placer, recorriendo con sus propias manos todo su cuerpo y diciendo: ¡por esto! Las otras trans* aplaudieron y festejaron su respuesta a carcajadas.

El cuerpo es el producto, la palapa es el escaparate del producto en el que se exhibe, frente a las miradas silenciosas de todos los que se encontraban ahí. ¿Qué tipo de producto es el cuerpo en este contexto? En este caso, el cuerpo es el producto de las intervenciones, los tránsitos, las violencias, el deseo de transformación y es también el producto de consumo e intercambio en el trabajo sexual. El cuerpo es el producto y no el punto de partida. Se trata de un efecto de operaciones de muy diversos órdenes: simbólicas, imaginarias, discursivas y también intervenciones en la carne. El cuerpo es un producto del deseo que aparece entre sujetos, no en el sujeto. El producto también de la experiencia misma, esa que no se alcanza nunca como objeto acabado, sino siempre en el hacer-se.

La "Palapa del Producto" hizo del círculo formado por una base de cemento y un techo de palma algo más. Este espacio, que reunía a un grupo de mujeres trans* y hombres gays, dentro del albergue, decidió nombrarse más allá de las siglas que identifican establemente las identidades de la diversidad sexual. Este grupo decidió nombrarse a partir del cuerpo y la posibilidad de hacer deseo en el lazo con otros y frente a la mirada de otros. ¿Qué tipo de productos pueden ser los cuerpos de las personas del módulo LGBTI que permite que se reconozcan como un nuevo grupo? ¿Qué hay en el entre de estos cuerpos que hace que se reúnan 
en esa palapa-círculo a partir de una experiencia compartida del cuerpo? Pensemos que se tratan de vidas que han atravesado un exilio permanente también a causa de muchas prácticas, imágenes y usos buscados en el cuerpo-producto. Son cuerpos que se producen desde otros lugares, otras experiencias eróticas, familiares y sociales, así como otras formas de nombrarse.

En la "Palapa del Producto" sobresalía, de forma llamativa, el uso afectivo que se hacía de este espacio y del cuerpo, que contrastaba con el resto de la casa. En esta palapa había caricias, abrazos, besos, cuerpos que se tocaban para demostrarse afecto. Eran cuerpos que se movían llamativamente con risas, gritos y movimientos dramáticos que demandaban las miradas de los otros. El contraste con el resto del espacio era muy marcado, ya que en el resto de las palapas sólo había conversaciones discretas y muchas miradas en silencio. Esa Palapa era un espacio donde el deseo circulaba de otra forma.

Podemos decir que el módulo LGBTI estaba conformado por hombres gays y mujeres trans*, pero la "Palapa del Producto" estaba conformada por culeros. En su cotidiano, las personas de la comunidad LGBTI se identificaban y nombraban entre ellos mismos en masculino como culeros. "Una mujer trans* es un culero, un hombre gay también es un culero, pero una lesbiana, por ejemplo, no puede ser culera", me explicaban ellos mismos.

Culero es una palabra que en Centroamérica señala, de manera despectiva, a un hombre con una masculinidad poco viril. Esta palabra incluye a hombres gays y a mujeres trans*. No incluye a las mujeres lesbianas, pues se dirige sólo al cuerpo de varón. Además, concierne a una posición frente al deseo sexual de ese cuerpo de varón: hombres y mujeres trans* (identificadas como varones de nacimiento) con preferencia sexual por otros hombres. Ser culero, también, es un insulto que aparece como sinónimo de cobardía, de una virilidad cuestionada que no corresponde con los mandatos de la masculinidad y que, por esto, pierde valor. Además, resulta obvia la referencia cercana al orificio anal del cuerpo -el culo- y, por lo tanto, su penetración, designando una posición pasiva en el acto sexual entre dos hombres, al mismo tiempo que una zona erógena prohibida para el goce sexual masculino. Se trata de señalar una feminización masculina, además de llamar a la vergüenza y recriminación por el uso del cuerpo de varón para la penetración, por identificar ahí también una feminización en el deseo.

Los integrantes de la "Palapa del Producto" decían, cuando hablaban de ellos mismos, que los culeros son traicioneros, difíciles, convenencieros, manipuladores y muy problemáticos. La connotación peyorativa que en Centroamérica tiene el adjetivo culero se desplaza de 
diferentes formas. El culero es el hombre afeminado y cobarde al que se hace referencia desde el insulto, pero que se posiciona como una subjetividad cargada de agresión y hostilidad cuando se hace propia.

Entre las personas de la "Palapa del Producto" se nombraban culeros, era el nombre que han escuchado como insulto desde siempre, pero además era el nombre con el que se identificaban y hablaban de sí mismos. Sin embargo, esto no quiere decir que los cuerpos y singularidades de las mujeres trans* quedaran invisibles o indiferenciadas entre ellos. El cuerpo era lo que ubicaba la diferencia para ellas mismas: los procesos de hormonización, el gusto por el maquillaje, la ropa de mujer, el pelo largo y el deseo de ser una mujer, tal como ellas lo describían. Los hombres culeros-gays no compartían los procesos de hormonización que sí compartían los culeros-trans*.

Las mujeres trans* ubicaban una transición de pasar de culeros-gay a culeros-trans* en edades tempranas. Sin embargo, la realidad es que esta diferencia estaba más en una dimensión subjetiva que se arma en un relato a posteriori sobre la trasgresión de un ordenamiento del género en lo social, pero no como una identidad política nombrable como tal desde esas edades. Muchas de estas mujeres, cuando hablaban de ellas mismas, intercambiaban fácilmente el género femenino y el masculino, aunque se posicionaran como mujeres. También se nombraban como trans* o culero indistintamente, sin que esto problematizara el campo de sus nuevas identificaciones. Lo que parece significativo, entonces, es ubicar cómo es que muchas de ellas no conocían la palabra trans* como identidad sexual, pero con el cruce de una frontera y la llegada a La 72 que las incluye en un nuevo universo de discursos políticos, aparece un ordenamiento discursivo que las ubica en una categoría nueva y que resulta favorable para posicionarse como una identidad política garante de derechos y de reconocimiento de protección a nivel internacional.

\subsection{La bandera LGBTI: el arcoíris desordenado}

El inicio de este trabajo de campo coincidió con el inicio de la pintura de un mural colectivo sobre la barda más larga del albergue ubicada en el espacio común más utilizado y concurrido. Por lo tanto, el mural ocupaba un lugar privilegiado para su contemplación. El proyecto era dirigido por una muralista, pero con la intención de que todas las personas migrantes pudieran integrarse y fueran parte activa de su elaboración.

Periódicus, Salvador, n. 12, v.1, nov.2019-abr.2020 - Revista de estudos indisciplinares em gêneros e sexualidades Publicação periódica vinculada ao Núcleo de Pesquisa NuCuS, da Universidade Federal da Bahia - UFBA ISSN: 2358-0844 - Endereço: http://www.portalseer.ufba.br/index.php/revistaperiodicus 
Las mujeres trans*, de manera orgullosa, mostraban los bocetos creados para la pintura del mural. La principal emoción era que este mural llevaría la bandera LGBTI en la parte central, junto con las banderas de El Salvador, Honduras y Guatemala. Con esta bandera en el centro, ellas se volverían parte central también de la ejecución del mural. Al momento de pintar la bandera LGBTI, el grupo de la "Palapa del Producto" se movía a lo largo de toda la casa. Llevaban y traían herramientas, usaban la pintura, probaban colores, ponían música, bailaban, se abrazaban y disfrutaban de llevar la batuta en este proyecto creativo. La bandera del arcoíris fue la primera que se trazó sobre el muro, lista para ser pintada. Todos los miembros de la "Palapa del Producto" quisieron participar de este evento y decidieron dividir la tarea: cada línea de color de la bandera sería pintada por una pareja, formada por una mujer trans* y un hombre gay. Festivamente eligieron a sus parejas y el color que cada una pintaría. La primera pareja comenzó a pintar, tomó un color y dio los brochazos iniciales. Alguien más notó que el color elegido no era el correcto, de acuerdo con la bandera original. Todos observaron el error, mientras comparaban la bandera recién pintada con la bandera que colgaba desde balcón del módulo LGBTI como referencia correcta. La comparación confirmaba el equívoco. Entre risas y vergüenza, se evidenció que quienes eran parte del módulo LGBTI no conocían el orden, ni los colores de la bandera que tomaban como estandarte de representación. Las carcajadas aparecieron, comenzaron las burlas entre ellas mismas y decidieron enmendar el error pintando por encima con los colores correctos. El desorden apareció desde el primer brochazo, se desorganizaron los colores de una bandera que intenta representar algo que es del orden de lo no organizable: la sexualidad.

El error de colores fue enmendado, pero la marca de este error quedaba visible. Sin embargo, a todas ellas les parecía la bandera más bonita que había pintada en la casa. El error en los colores y la mancha fácilmente perceptible no parecía importarles. Esa bandera del mural pintada por la "Palapa del Producto" no era igual a la bandera de fábrica que colgaba del módulo LGBTI. Había algo muy significativo en esa imagen: la hicieron propia desde el equívoco y la mancha.

Podríamos decir que la bandera original que colgaba del balcón identificaba al módulo LGBTI como producto de una organización propia de la casa. Identificaba también a esas mismas identidades políticas reconocidas bajo las siglas LGBTI. Esa bandera original era un objeto del espacio construido por el albergue y por los discursos internacionales sobre las políticas de identidad sexual. La bandera pintada por ellas mismas en el mural, con los colores 
desorganizados y las manchas visibles, identificaba a la "Palapa del Producto", es decir, a ese grupo contingente que aparece en el tránsito, con procesos de adscripciones diversas en el espacio geográfico, social y político en el que se encontraban.

El despliegue que las mujeres trans* hicieron de sus cuerpos, sus movimientos y sus voces por toda la cancha mientras pintaban y el resto de los hombres del albergue observaban, no fue un evento secundario, sino que fue la condición para que esa bandera desordenada y equívoca diera la oportunidad a la "Palapa del Producto" de tomar un lugar protagónico y pasar de la periferia a un centro momentáneo, aunque también permanente, en los murales de las paredes de la casa. En esta serie de movimientos se produjo un cambio de posición, los culeros se volvieron el centro de las miradas, en un nuevo tipo de ordenamiento de poder frente al resto de los migrantes que ahí se encontraban.

También estaban las imágenes de las tres banderas que representan a las naciones del triángulo norte: Guatemala, Honduras y El Salvador y, de manera reciente, se incorporaba una bandera más a este triángulo: la bandera LGBTI o de la diversidad sexual. Como si se tratara de una nación diferente o de un pueblo sin nación, que no puede representarse con las banderas de los países expulsores en este contexto.

Así como estos eventos, en el trabajo de campo aparecieron múltiples trasposicionamientos para pensar cómo el deseo de este grupo y su circulación singular producían formas sociales particulares, desde las que se apropiaban discursos y espacios, al mismo tiempo que se fisuraban y producían otros. Se producía además un espacio que, al mismo tiempo que las posicionaba como un colectivo con poder y derechos dentro de los espacios sociales de las instituciones, les implicaba una negociación permanente en sus adscripciones identitarias.

Parte de estas negociaciones, que implican un reposicionamiento subjetivo y social, aparecen articuladas con la figura del reconocimiento de la condición de refugiadas, lo cual convierte a la huida y el desplazamiento errático en un proyecto político con nuevas motivaciones y con una exigencia de derechos relacionada, íntimamente, con su experiencia trans*. Ya no se esconden de un Estado que las convierte en indocumentadas, sino que se le interpela demandando la protección internacional a causa de las violaciones sufridas por ser parte de una comunidad sexual que se adscribe desde lo periférico. 
Al respecto de estas discusiones retomamos lo que Falconi Trávez \& Viteri (2014) nombran como una traducción de las fronteras sexuales y raciales que es necesaria para ajustar ciertas posiciones identitarias en la llegada a los destinos migratorios. Esto implica simultáneamente una asimilación a dicha cultura, como también un reconocimiento de la agenda que la acompaña, considerando que esta agenda no es universal y que presenta una fuerte ambivalencia con relación a las diferencias étnicas y raciales.

En el argumento de Falconi Trávez \& Viteri (2014) se piensa que, al entrelazar una discusión de identidades LGBTI con una discusión sobre el género y la diáspora, se hace aún más visible el poder que tiene el discurso para realizar aquello que nombra. En este sentido, el poder actúa como discurso.

En este sentido advertimos también un desplazamiento en los marcos de la ciudadanía de los culeros que se reconfigura desde la categoría trans*, junto con un nuevo marco de políticas sexuales transnacionales, en diálogo con otras figuras migratorias como lo son la de refugiado que, necesariamente, organizan de otra forma el tránsito y la configuración subjetiva que se produce en él.

Estos espacios de tránsito se han caracterizado como momentos de reajustes de una trayectoria (Collyer \& De Haas, 2012), espacios de espera que marcan una aparente inmovilidad dentro de un proceso móvil (Schapendonk, 2012). Aquí se considera un espacio temporal complejo que aparece no sólo como la espera para una transformación sino como la transformación misma.

En palabras de Musset (2015), lejos de ser fluidos, homogéneos o lineales, los desplazamientos de distinta índole que caracterizan a las sociedades contemporáneas están marcados por tiempos y momentos más o menos largos de espera. Su origen puede ser por razones técnicas, administrativas o políticas, y a menudo tales momentos encuentran una traducción espacial. De ahí la importancia que tiene para analizar estos territorios de la espera/tránsito/permanencia y la multiplicidad de formas que revisten, el ejercicio de calcular sus dimensiones, definir sus estatutos jurídicos, sus articulaciones con el espacio circundante, sus temporalidades específicas, así como la variedad de los procesos sociales que se despliegan en su marco (Musset, 2015). 
El atravesamiento de la frontera mexicana produce matices significativos en los desplazamientos forzados trans*fronterizos de estas mujeres. Por un lado, pasan de ser extranjeras, a ser migrantes ilegalizadas por las exigencias estatales para el cruce de fronteras y, posteriormente, solicitantes de la condición de refugiadas. Al mismo tiempo, transitan de una identificación social como culeros a ser parte del colectivo LGBTI. En estos cambios y esperas se producen nuevas adscripciones políticas en relación con las identidades sexuales y se imponen nuevas temporalidades en su transición corporal, lo que nuevamente articula las condiciones de su transitar con la experiencia subjetiva del cuerpo, la sexualidad y el género.

La espera de estas mujeres trans* en el albergue, donde inician el trámite de solicitud de refugio, impone tiempos burocráticos a sus vidas, sus cuerpos y sus expresiones sexuales y de género, pero también permite explorar otro tipo de vínculos, de experiencia intersubjetiva y de producción de discursos sobre sus identidades y las dimensiones políticas de las identidades sexuales.

\section{Conclusiones}

En el presente artículo se ha tenido el objetivo de caracterizar los desplazamientos que las mujeres trans* centroamericanas vienen realizando hasta antes de su llegada al albergue para migrantes La 72, en Tenosique. En este recorrido se han analizado las formas en que se articula el desplazamiento geográfico con su transición de género, para demostrar que se trata de un desplazamiento que tiene condiciones y coordenadas muy particulares que no se alcanzan a comprender desde los relatos clásicos de la migración que se han producido sobre la región.

Hemos propuesto el concepto de "desplazamiento forzado trans*fronterizo" para caracterizar las particulares y complejas motivaciones (en tanto deseadas y, otras, en tanto forzadas) que configuran este desplazamiento. Para esto, los relatos de mujeres trans* encontradas en La 72 permiten ver un contexto de expulsión permanente de diversos espacios y que, al mismo tiempo, muestran cómo estas expulsiones fueron encontrando otros espacios y tránsitos en donde la experiencia trans* pudo producirse, lo que termina configurando un escenario particular en sus motivos de salida, tránsito y llegada, de manera siempre procesual y nunca lineal.

Con la presentación de estas experiencias se puede distinguir la complejidad de tránsitos que atraviesan una vida en desplazamiento forzado, que hasta ahora han quedado opacados dentro de los análisis sobre la migración en tránsito que atraviesa por México. Las trayectorias 
que estas vidas presentan no corresponden al estado de la cuestión que existe sobre la migración centroamericana que atraviesa México con la idea de llegar a Estado Unidos.

En el caso de la población trans* no existe un proyecto migratorio sostenido por un hábitus migratorio regional. En el caso de estas personas, la expulsión de un entramado social comienza a temprana edad por el rechazo familiar experimentado y a partir de ahí se desarrolla desde una marginalidad vinculada con el ejercicio del trabajo sexual en la calle, durante la noche y en la exposición de amenazas continuas por parte de diversos actores.

Todo esto configura un panorama que va exigiendo huidas permanentes, al mismo tiempo que se busca una transformación. Sin embargo, esta transformación, del ordenamiento de género y sexual, tiene matices muy singulares que no pueden ser explicados desde un mismo lugar de llegada. En los relatos de las mujeres trans*, si bien hay puntos de encuentro de un lugar de ser mujer que es buscado, también hay particularidades que escapan de un lugar totalizante del hacer-se mujer.

El conocimiento de una comunidad LGBTI y las posibilidades de solicitar refugio, debido a la misma violencia que ha representado su expresión sexual y de género, va produciendo también un nuevo posicionamiento desde donde el respeto puede ser exigido. En esta discusión podemos preguntarnos: ¿qué tipo de sujetos políticos se están produciendo en estos tránsitos y en estos espacios con discursos específicos sobre la diversidad sexual y los derechos humanos?

En la propuesta de este trabajo, estos territorios de la espera configuran una temporalidad particular, que se impone desde los trámites de la regularización migratoria y que se materializa en el cuerpo y en los procesos vinculares de estas mujeres trans* para retramitar su cuerpo, sin el acceso a los tratamientos hormonales, ni al ejercicio del trabajo sexual. Sin embargo, aparece una nueva forma de seguir elaborando su experiencia trans* y los nuevos posicionamientos como refugiadas, desde ideales de un lugar de llegada que no existía previamente al iniciar el tránsito fronterizo, ni mucho menos en el inicio de su transitar sexual.

A partir de este recorrido, podemos formular nuevas preguntas que nos permitan pensar cómo continúan los viajes y las trayectorias después de que se otorgan estos reconocimientos como refugiadas: ¿qué nuevos exilios pueden aparecer ahí? y, ¿qué lugares de alojamiento se producen? Además, este recorrido permite continuar explorando qué pasa en los procesos de llegada a ciudades donde los marcos legales protegen a la comunidad LGBTI de diversas formas de discriminación, pese a que la violencia y la exclusión siguen marcando sus vidas. 
En este sentido, se puede concluir que la experiencia trans* atraviesa y sostiene el desplazamiento de vida y migratorio de estas mujeres. Esta experiencia trans* aparece como la razón de la expulsión que se padece desde los vínculos familiares y comunitarios; el ejercicio del trabajo sexual como único espacio frente a estas expulsiones de lo social; y el padecimiento de violencia recrudecida en los espacios del trabajo sexual y los espacios cotidianos en que transcurren sus vidas y sus cuerpos feminizados. Por otro lado, esta misma experiencia trans* es también el articulador de sus motivaciones para continuar en este tránsito geográfico, es decir, otorga sentido y significado de los objetivos buscados en el desplazamiento, así como en sus reacomodos en los tiempos de espera. En esta búsqueda se construye un ideal que articula espacios subjetivos y corporales, con espacios geográficos y simbólicos a los que se busca llegar. Se espera llegar tanto a un ideal de mujer a partir de la intervención de sus cuerpos, como a una ciudad, en este caso la Ciudad de México, que permita habitar esta experiencia trans* sin poner en riesgo la vida. El tránsito de género desencadena el desplazamiento, pero, también, encuentra en este mismo desplazamiento un movimiento constante y necesario para la búsqueda de la transformación deseada.

Estos tránsitos corresponden a un flujo muy particular y densamente complejo, con lógicas, significaciones, procesos vinculares y sentidos que se separan de las lógicas de otros movimientos migratorios que también suceden en la región. En este desplazamiento, además de su carácter forzado por la violencia recrudecida que padecen estas mujeres, aparece un proyecto que se transita en el cuerpo mismo y, con esto, un panorama de adscripciones identitarias, posiciones subjetivas, así como reconfiguraciones del género y del ordenamiento sexual.

A partir de estas conclusiones es necesario considerar nuevas preguntas donde podría resultar interesante ubicar las relaciones de las fantasías de los ideales del hacer-se mujer y la fantasía sobre la llegada a la Ciudad de México con las experiencias reales que aparecen en este nuevo espacio cuando se está ahí. ¿Qué tipos de flujos o circuitos se abren a partir del atravesamiento de la frontera formal mexicana y el reconocimiento de su estatus como refugiadas? ¿Cómo se reconfigura la relación con el tránsito libre y la producción de nuevas fronteras internas relacionadas con las disposiciones interseccionales de estas mujeres?

Finalmente, con esta investigación se abrió la exploración sobre el campo del deseo y lo sexual como dimensión para explorar los desplazamientos de cuerpos que escapan del ordenamiento del género en relación con la diferencia sexual. En este sentido convendría 
sostener la pregunta de cómo este campo de indagación sobre el deseo puede aportar otras formas analíticas para la comprensión de la experiencia trans*, en tanto campo de producción emergente en los estudios de género.

\section{Referências}

ACNUR (Alto Comisionado de las Naciones Unidas para los Refugiados) (2008), "Nota de orientación del ACNUR sobre las solicitudes de la condición de refugiado relacionadas con la orientación sexual y la identidad de género", informe, texto completo, URL: http://www.refworld.org/cgi$\mathrm{bin} /$ texis/vtx/rwmain/opendocpdf.pdf?reldoc=y\&docid=49b689382, última consulta marzo 2018.

BRAH, Avtar (2013) "Pensando en y a través de la interseccionalidad" En La interseccionalidad en debate. Actas del Congreso Internacional. Indicadores Interseccionales y Medidas de Inclusión Social en Instituciones de Educación Superior, editado por Martha Zapata Galindo, Sabina García Peter y Jennifer Chan de Avila, 14-20. Berlin: Freie Universität Berlin.

BUTLER, Judith (2001b), El género en disputa. El feminismo y la subversión de la identidad, México-Buenos Aires-Madrid, Paidós.

CABRAL, Mauro (2009), "Asterisco", en M. Cabral, Interdicciones. Escrituras de la intersexualidad en castellano, Córdoba, Anarrés Editorial, p. 14.

CALDERÓN CHELIUS, Leticia y ANDREA, González Cornejo (2012), Rastros del duelo: exilio, asilo político y desplazamiento forzado interno en la frontera norte de México, texto completo URL: http://acad.colmex.mx/sites/default/files/pdf/Calder\%C3\%B3n-Gonz\%C3\%A1lezRastros-del-duelo.pdf, última consulta junio 2018.

COLLYER, Michael; De Haas, Hein (2012), "Developing Dynamic. Categorizations of Transit Migration", Population, Space and Place, 18, p. 468-481.

COMAR (Comisión Mexicana de Ayuda a Refugiados) (2019), "Boletín estadístico Solicitantes de Refugio en México" informe, texto completo, https://www.gob.mx/comar/articulos/la-comar-en-numeros?idiom=es, última consulta agosto 2019.

COTTEN, Trystan (ed.) (2012), Transgender Migrations. The Bodies, Borders, and Politics of Transition. New York y Londres: Routledge.

CIDH (Comisión Interamericana de Derechos Humanos) (2015), "Violencia contra personas LGBT", Organización de los Estados Americanos, informe, texto completo, URL: http://www.oas.org/es/cidh/informes/pdfs/violenciapersonaslgbti.pdf , última consulta enero 2018.

CIDH-Honduras (Comisión Interamericana de Derechos Humanos) (2015), "Situación de Derechos Humanos en Honduras", Honduras, CIDH-OEA.

DOAN, Petra (2010) "The tyranni of gendered spaces, reflections from beyond the gender dichotomy", Gender, place and culture, 17(5), pp. 635-654.

FALCONI TRÁVEZ, Diego; SANTIAGO, Castellanos y VITERI, María Amelia, (2014), Resentir lo queer en América Latina: diálogos desde/con el sur, Barcelona, Egales editorial. 
FERNÁNDEZ BESSA, Cristina (2008), "Los límites del control”, en C. Fernández y M. Mazkiaran, Frontera sur. Nuevas politicas de gestión y externalización del control de la inmigración en Europa, Barcelona, Virus editorial, pp. 6-13.

GÓMEZ-JOHNSON, Cristina. (2015), "De la migración económica a la migración forzada por el incremento de la violencia en El Salvador y México", Estudios Políticos, 47, Instituto de Estudios Políticos, Universidad de Antioquia, pp. 199-220.

GONZÁLEZ GIL, Adriana (2015) "Del desplazamiento forzado interno en Colombia a la migración transfronteriza hacia Ecuador", texto completo URL: <http://www.redalyc.org/articulo.oa?id=16440055011>, última consulta junio 2018

HESS, Sabine (2012) "De-naturalizing Transit Migration. Theory and Methods of An Ethnographic Regime Analysis", Population, Space and Place, 18, pp. 428- 440.

HOGAR-Refugio para Personas Migrantes, La 72 (2017), "En los límites de la frontera, quebrando los límites: situación de los derechos humanos de las personas migrantes y refugiadas en Tenosique, Tabasco", Pies Descalzos, informe, texto completo, URL: http://sercatol-cp5014.wordpresstemporal.com/wp-

content/uploads/2017/04/Informe-DDHH-2016-LA-72.pdf, última consulta abril 2018 .

KÄLIN, Walter (2005), Addressing Internal Displacement: A Framework for National Responsibility, Washington, D. C., The Brookings Institution-University of Bern.

MALO, Marta (2006), Fronteras interiores/exteriores apuntes de contrapoder, texto completo, URL: https://nocionescomunes.files.wordpress.com/2010/11/fronterasexternas-internas.pdf, última consulta abril 2018.

MUSSET, Alain (2015), "De los lugares de espera a los territorios de la espera ¿Una nueva dimensión de la geografía social?" Documents d'Anàlisi Geogràfica 2015, vol. 61/2, pp. 305-324.

OBSERVATORIO de Protección Internacional, (2019), "El género como causal de reconocimiento de la condición de refugiado en el sistema de asilo mexicano", Universidad Iberoamericana, México, texto completo, URL: file:///Users/alixalmendra/Desktop/ibero-2018-informe-el-genero-como-causal.pdf, última consulta abril 2019.

OIM (Organización Internacional para las Migraciones) (2016), "Migrantes en México: vulnerabilidad y riesgos", Tijuana, OIM y el Colegio de la Frontera Norte.

PICHARDO, José Ignacio (2003), "Migraciones y opción sexual”, en: Guasch, Óscar y Olga Viñuales (eds.), Sexualidades. Diversidad y control social. Barcelona: Bellaterra, pp. 277-297.

PONS RABASA, Alba (2016), "Género 3.0. Frontera y multitud", Multidisciplinary Journal of Gender Studies, 5(2), pp. 1014-1038.

REDODEM (Red de Documentación de las Organizaciones Defensoras de Migrantes) (2014), "Migrantes invisibles, violencia tangible", México.

SCHAPENDONK, Joris (2012) "Migrants im/mobilities on their way to the EU: Lost in transit?", Tijdschrift voor Economische en Sociale Geografie, 103(5), pp. 577-83.

TRANSGENDER EUROPE, (2017), "Observatorio de Personas Trans Asesinadas", URL: http://transrespect.org/es/, última consulta julio 2018.

VARTABEDIAN CABRAL, Julieta (2012). Sobre travestis, clientes y maridos: género y sexualidad en la construcción de las identidades de travestis brasileñas trabajadoras del sexo. Revista de Antropología Social, 23.

VILLALOBOS, Hazel, (2017), "Tasas de homicidios en Centroamérica del 2006 al 2016: balance de una década", Fundación para la Paz y la Democracia, URL: https://pensandodesdecentroamerica.wordpress.com/2017/01/19/tasas-dehomicidios-en-centroamerica-del-2006-al-2016-balance-de-una-decada/, última consulta julio 2018 .

WOLA (Oficina en Washington para Asuntos Latinoamericanos) (2017), "La Frontera Sur de México. Seguridad, migración centroamericana y políticas estadounidenses", 
texto completo, URL: https://www.wola.org/wp-content/uploads/2017/06/WOLAFrontera-sur-de-Mexico-2017.pdf, última consulta mayo 2018. 